\title{
Análise das estratégias empresariais no contexto de pós pandemia de COVID-19
}

\author{
Analysis of business strategies in the context of post-pandemic COVID-19 \\ Análisis de estrategias de negocio en el contexto del COVID-19 post-pandemia
}

\author{
Eneida Guerra Silvestrim \\ ORCID: https://orcid.org/0000-0001-8392-1486 \\ Universidade Federal do Amazonas, Brasil \\ E-mail: egsilvestrim@gmail.com \\ Michael Raphael Soares Vieira \\ ORCID: https://orcid.org/0000-0002-1436-8936 \\ Universidade Federal do Amazonas, Brasil \\ E-mail: michael.soares.vieira@gmail.com \\ Fernanda Guerra Silvestrim \\ ORCID: https://orcid.org/0000-0002-7571-9795 \\ Faculdade Estácio do Amazonas, Brasil \\ E-mail: ca.ecologica@gmail.com \\ Arlindo Almeida De Lima Filho \\ ORCID: https://orcid.org/0000-0003-0754-0723 \\ Instituto de Pós-graduação e Graduação, Brasil \\ E-mail: arlindo.almeida.filho@gmail.com \\ Aixa Braga Lopes \\ ORCID: https://orcid.org/0000-0002-4680-6814 \\ Instituto Nacional de Pesquisas da Amazônia, Brasil \\ E-mail: lopesaixa@gmail.com
}

\begin{abstract}
Resumo
Algumas empresas em todo mundo aplicam de forma corriqueira medidas de desenvolvimento em estratégias de negócios. A pandemia de COVID-19, provocada pelo novo corona vírus, além de causar perdas de vidas, afetou diretamente a economia mundial e forçou as empresas a se adaptar neste contexto de pandemia. Diante desta problemática, o objetivo geral deste trabalho foi identificar quais as estratégias empresariais que as empresas de nível local, regional e internacional aplicaram para se adaptar no contexto da pandemia do COVID-19 no mundo. Este artigo optou pela metodologia qualitativa, foi utilizado a pesquisa bibliográfica, para melhor abordar os problemas enfrentados pelas corporações, identificando procedimentos para ter resiliência diante desta nova realidade. Como resultado, as empresas passaram a buscar ajuda em bancos através de novas linhas de crédito oferecidas pelos governos, adaptar-se a decretos em novos horários de trabalho e a alternativas trabalhistas que possibilitaram o afastamento temporário, redução de trabalho e salário e demissões com pagamento de rescisões parceladas, ou férias coletivas, a proceder ajustes nas condições higiênico sanitárias para que pudessem proceder com o atendimento ao público e elevar seus investimentos em mídias digitais. O estudo concluiu, que alguns segmentos, utilizando muitos esforços, apresentaram crescimento, trazendo certa estabilidade à economia e impulsionando a adoção de novas estratégias econômicas. Em contrapartida, ainda existem situações delicadas que merecem um olhar mais atento quanto ao nível de desemprego e combate à pobreza, que ainda se encontram em níveis muito elevados.
\end{abstract}

Palavra-chave: Economia; Planejamentos; Coronavírus; Empresa.

\begin{abstract}
Some companies around the world routinely apply development measures in business strategies. The COVID-19 pandemic, caused by the new corona virus, in addition to causing loss of life, directly affected the world economy and forced companies to adapt to this pandemic context. Given this issue, the general objective of this work was to identify which business strategies local, regional and international companies have applied to adapt in the context of the COVID-19 pandemic in the world. This article opted for a qualitative methodology, bibliographical research was used to better address the problems faced by corporations, identifying procedures to have resilience in the face of this new reality. As a result, companies started to seek help from banks through new lines of credit offered by governments, adapting to decrees in new working hours and working alternatives that allowed temporary leave, reduced work and salary, and paid layoffs from rescissions in installments, or collective vacations, to make adjustments in the hygienic and sanitary conditions so that they could proceed with the service to the public and increase their investments in digital media. The study concluded that some segments, using a lot of efforts, showed growth, bringing some stability to the economy and driving the adoption of new economic strategies. On the other
\end{abstract}


hand, there are still delicate situations that deserve a closer look at the level of unemployment and the fight against poverty, which are still at very high levels.

Keyword: Economy; Planning; Coronaviruses; Company.

\begin{abstract}
Resumen
Algunas empresas de todo el mundo aplican de forma rutinaria medidas de desarrollo en sus estrategias comerciales. La pandemia COVID-19, provocada por el nuevo virus corona, además de provocar pérdidas de vidas, afectó directamente a la economía mundial y obligó a las empresas a adaptarse a este contexto pandémico. Ante esta problemática, el objetivo general de este trabajo fue identificar qué estrategias comerciales han aplicado las empresas locales, regionales e internacionales para adaptarse en el contexto de la pandemia COVID-19 en el mundo. Este artículo apostó por una metodología cualitativa, se utilizó la investigación bibliográfica para abordar mejor los problemas que enfrentan las corporaciones, identificando procedimientos para tener resiliencia ante esta nueva realidad. Como resultado, las empresas empezaron a buscar ayuda de los bancos a través de nuevas líneas de crédito ofrecidas por los gobiernos, adaptándose a decretos en nuevas jornadas y alternativas laborales que permitían licencia temporal, reducción de trabajo y salario, y despidos pagados por rescisiones en cuotas, o colectivas. vacaciones, para hacer ajustes en las condiciones higiénicas y sanitarias para que puedan proceder con el servicio al público y aumentar sus inversiones en medios digitales. El estudio concluyó que algunos segmentos, con muchos esfuerzos, mostraron crecimiento, aportando cierta estabilidad a la economía e impulsando la adopción de nuevas estrategias económicas. Por otro lado, aún existen situaciones delicadas que merecen una mirada más cercana al nivel de desempleo y la lucha contra la pobreza, que aún se encuentran en niveles muy altos.
\end{abstract}

Palabra clave: Economía; Planificación; Coronavirus; Empresa.

\title{
1. Introdução
}

Para a Organização Mundial da Saúde (OMS), COVID-19 foi o nome definido para a doença oriunda do novo coronavírus que deu início, em março do ano de 2020, a uma pandemia mundial. A descrição técnica para o novo vírus, conhecida como SARS-CoV-2, foi denominada a partir do Comitê Internacional de Taxonomia de Vírus, devido às suas semelhanças com o coronavírus (CoV) causando a Síndrome Respiratória Aguda Grave, que ainda afeta mundialmente a economia, forçando as empresas a se adaptarem neste contexto de pandemia (OPAS, 2020; de Morais \& de Almeida, 2021).

A Pandemia do COVID-19, mudou a realidade global à medida que obrigou a imposição de restrições ao modo de cada indivíduo levar sua vida, em suas relações sociais, de trabalho e na sua maneira de consumir. Corporações internacionais e companhias nacionais de grande porte, perante uma crise, colocam em prática de forma corriqueira, medidas com desenvolvimento de estratégia de negócios, sendo essa uma realidade diferente para as pequenas e médias empresas, na qual desprezam uma devida atenção ao desenvolvimento de estratégias. Temos como exemplo empresas que apenas procuram desenvolver o plano de negócios na necessidade de um financiamento bancário, enquanto outras, passam a utilizá-la como uma tendência de mercado, seguindo modelos de concorrentes (Oliveira et al.,2020; Pimentel \& Silva, 2020; Alves et al., 2020).

No Brasil, as mudanças econômicas foram deliberativas no desenvolvimento dos indicadores, devido a um grupo de doenças que afetaria a saúde pública e consequentemente, a economia do país. Nos últimos 50 anos o Brasil suportou profundas transformações, houve a duplicação em sua população chegando a 200 milhões de habitantes (IBGE, 2020).

As pessoas, de fato, tendem a mudar seus comportamentos quando são afetadas por novos e, principalmente, inesperados acontecimentos e esse é um aspecto essencial observado em fenômenos de pandemia. Durante períodos de risco de saúde, como em pandemias, essa tendência se agrava. Os indivíduos tendem a buscar lugares longe de aglomerações, para evitar contato com possíveis infectados. Na pandemia de COVID-19, o isolamento social e, em alguns casos, o lockdown (paralisação rígida com controle dos fluxos de deslocamentos), como vários decretos pelo Brasil e pelo mundo, provocaram uma significativa alteração nos comportamentos de compra dos consumidores, afetando diversas categorias de negócios Chauhan e Shah (2020). O consumo é um hábito que depende do contexto do momento e alguns fatores podem afetá-lo. Socialmente (novo estado civil), tecnologicamente (compras virtuais), legalmente (novas regras e leis) e por desastres naturais (como uma pandemia) e, como os consumidores improvisam no novo contexto, as empresas precisam improvisar para 
acompanhá-los, sendo criadas então novas estratégias, novas formas de logística e essas empresas precisarão acompanhar a evolução Sheth, (2020). Portanto, embora muitos desses hábitos voltem ao normal, outros serão modificados permanentemente Moretti et al. (2021).

A partir deste cenário, o país foi afetado com o aparecimento desse vírus popularmente conhecido por "novo coronavírus", que assolou o mundo de forma geral e rápida e forçou a todos o isolamento.

Diante desta problemática, este trabalho teve como objetivo geral identificar quais as estratégias empresariais que as empresas de nível local, regional e internacional utilizaram para se adaptar ao contexto da pandemia do COVID-19 no mundo.

\section{Metodologia}

Este artigo optou pela metodologia qualitativa, uma vez que a análise da situação atualizada é caráter exploratório de grande importância.

Foi utilizada a pesquisa bibliográfica, para melhor abordar os problemas enfrentados pelas empresas e corporações e identificar quais os procedimentos para driblar esta nova realidade, para que novas estratégias de negócios sejam apresentadas de forma atualizada e com veracidade de fatos.

A pesquisa bibliográfica dá um verdadeiro suporte em embasamento teórico para que possa ser compreendido por meio dos pensamentos dos autores o objeto em estudo, para que diante disso possam ser descritos os entendimentos do pesquisador. Silva (2003), explica e discute um tema ou problema com base em referências teóricas já publicadas em livros, revistas, periódicos e artigos científicos. A estratégia de busca sistematizada, possui como fundamento o levantamento de artigos científicos, para compor a fundamentação teórica da pesquisa (Estrela, 2018)

A análise da circunstância atualizada é de suma relevância, pois considera o pesquisador como parte integrante do processo, segundo Chizzotti (1995, p. 78) "A abordagem qualitativa parte do fundamento de que há uma relação dinâmica entre o mundo real e o sujeito, uma interdependência viva entre o sujeito e o objeto, um vínculo indissociável entre o mundo objetivo [...]"

Apesar de possuir dados quantitativos, possui uma ênfase descritiva que Silva (2014, p. 22) afirma "visa efetuar a descrição de processos, mecanismos e relacionamentos existentes na realidade do fenômeno estudado, utilizando, para tanto, um conjunto de categorias ou tipos variados de classificações"

Esta pesquisa segue uma cronologia narrativa, de trabalhos publicados após a Organização Mundial da Saúde (OMS), apontar o COVID-19 como uma pandemia, sendo de 11 de março de 2020, até os dias atuais. Utilizando como base científica artigos encontrados na Scielo e Google Scholar, tendo como critério de escolha trabalhos que descrevam experiências aplicadas de estratégias voltadas para o contexto da pandemia, aplicando exclusão para trabalhos sem sucessos, ou resultados inconclusivos.

\section{Resultados e Discussão}

\subsection{Impactos Econômicos}

A Pandemia do Novo Corona vírus impactou a economia mundial, e provocou uma crise catastrófica em diversos setores em todo o mundo, a bolsa de valores no Brasil, por exemplo, foi impactada e prejudicada antes mesmo do vírus chegar aqui. Os investidores tiveram uma ressaca de carnaval em 2020 um pouco mais pesada, quando a bolsa começou a despencar no final de fevereiro e chegou a cair 50\% do topo histórico.

No Brasil, segundo Barro et al. (2019) existe uma grande preocupação do governo e da sociedade quanto aos impactos econômicos. No início da Pandemia, era importante que a economia do país não ficasse estagnada por muito tempo. Primeiro, 
porque o desemprego aumentou mais de $11 \%$ somente em fevereiro de 2020, antes da crise chegar e esse número só cresceu nos meses subsequentes.

As inúmeras restrições que foram impostas por diversos Decretos estaduais e municipais por todo o país, de maneira a impedir a aglomeração de pessoas e tentar impedir a pandemia de se alastrar, paralisou o comércio e a indústria tradicional. E, essa paralisação do comércio tradicional, provocou um colapso em empresas tradicionais, que não estavam relacionadas a setores com permissão para funcionar, que eram principalmente as empresas de medicamentos e alimentos.

Os funcionários das empresas, por sua vez, tratam a pandemia COVID 19 e entendem o isolamento social como necessário, embora não desejável à população obrigada a permanecer em casa (Silva \&Pimentel 2021). Esse isolamento aumentou a demanda por bens de consumo como celulares, tablets, televisores, ar-condicionado e outros itens de uso doméstico.

Algumas empresas industriais encontraram formas para seguir trabalhando e, aproveitando-se de autorização especial de decretos, puderam seguir com a produção, como aconteceu com algumas empresas do Polo Industrial de Manaus.

Diante disso, os empregos formais pagaram o preço e o desemprego chegou a 14,4\% (IBGE, 2020). Não é possível atribuir tal acontecimento apenas ao fato da pandemia no Brasil ter tido dados alarmantes, o cenário econômico mundial contribuiu para esse contexto, pois o Brasil necessitava exportar para gerar emprego e renda para o país, além de recessões econômicas ou acordos internacionais já firmados.

A racionalidade dos negócios voltou, principalmente com a queda dos preços nas ações, mesmo assim as incertezas advindas do tempo de quarentena e os dados de contaminados e mortos pelo mundo, implicaram em muitas mudanças de estratégias empresariais.

No Brasil, houve uma expectativa de uma redução de 0,5\% no PIB para 2020. Porém em 2021 houve a projeção de expansão de 2,5\%, sem todos os dados concretos do impacto do coronavírus na economia, esse resultado trazia, desde o início, a perspectiva de um PIB negativo (Bastos \& Cajueiro, 2020).

Figura 1: Variação do PIB $2^{\circ}$ trimestre com relação dos países em 2021.

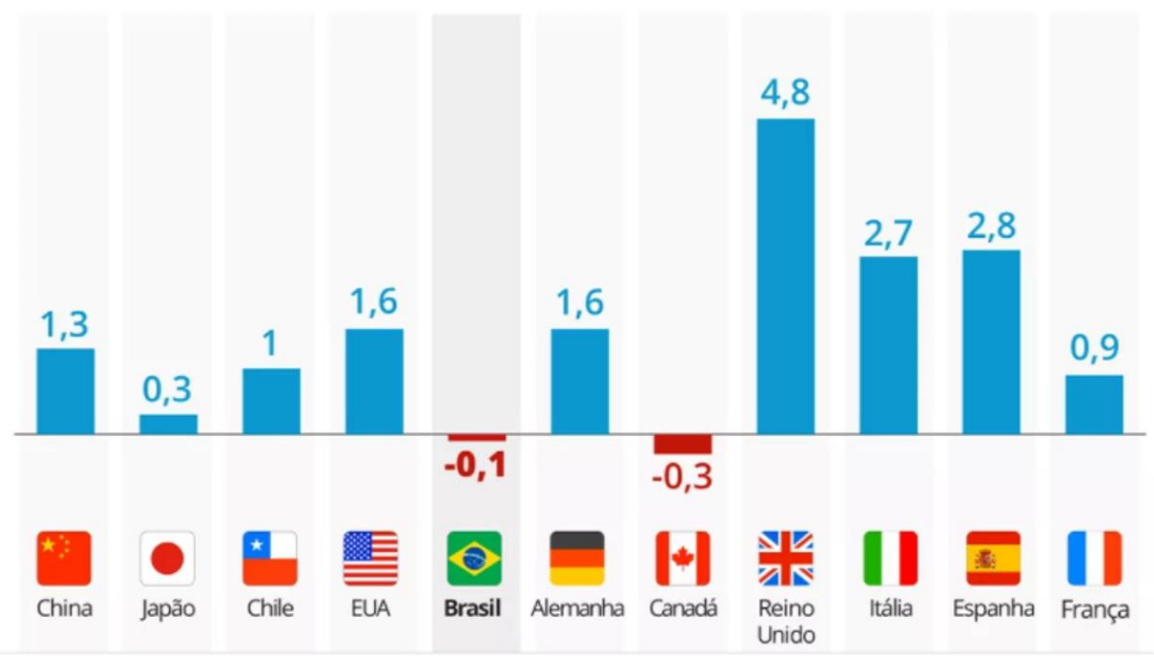

Fonte: Eurostat e Rating (2021).

Conforme a Figura 1 o PIB do $2^{\circ}$ trimestre quando comparado entre países mostra que o apesenta uma queda de $0,1 \%$, não tivemos recessões como a de algumas potências europeias, já a Figura 2 mostra que no 3 trimestre tivemos uma elevação de 7,5\% quase revertendo a situação do $2^{\circ}$ semestre, representando 1,3\% acima quando confrontado com o PIB de 2019. 
Por outro lado, com a população em casa, o comércio virtual, cresceu vertiginosamente, em detrimento do comércio tradicional e, como o comércio virtual emprega menos pessoas que processo tradicional, esse processo fez com que muitas empresas não se recuperassem, pois não havia como manter funcionários se precisavam permanecer fechados e sofreram prejuízos irremediáveis, como foi o caso de grandes lojas comerciais e grandes restaurantes, que detinham grande número de funcionários. Alguns desses magazines, como estratégia, adicionaram novos segmentos de produtos aos já existentes, para que pudessem atender às novas demandas e ao novo cenário logístico.

Enfim, uma vez que havia a permissão para venda por "delivery" para diversos tipos de produtos, sobreviveram os empreendedores que agiram rápido e utilizaram redes digitais para vender e entregar seus produtos. Isso fez com que uma mudança gigantesca acontecesse no mercado, antecipando a evolução das empresas para a era digital.

Figura 2: Taxa de Variação mensal do PIB mensal com relação ao ano anterior.

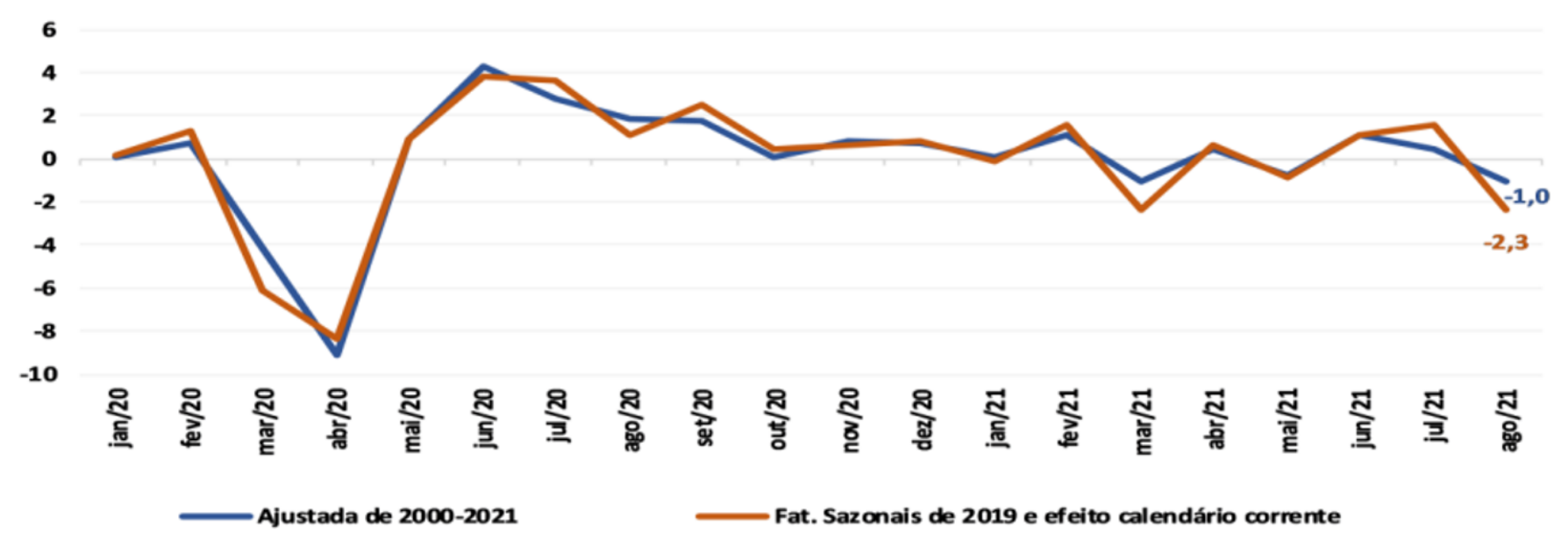

Fonte: FGV IBRE (2021).

Segundo Guimbeau et al. (2020), o Brasil ajusta técnicas econométricas com fatores de dados e documentação das últimas décadas, para avaliar as consequências da Pandemia Influenza em 2018 sobre a densidade demográfica, formação de capital humano e verificar os indicadores da produção nos estados. Além de apresentar a relevância da documentação histórica, a literatura mostra a ocorrência de efeitos fortes sobre a saúde e desempenho da educação e da produção nos próximos 20 anos após o período da pandemia. Seu trabalho apontou métodos para a potencial de grande magnitude do ponto de inflexão da economia brasileira, partindo no empenho da Pandemia COVID-19 no país.

Desdobramentos esses que se distanciaram de entidades mundiais como a OMS e entrando em desacordos entre os poderes executivos no país, uma vez que os governo federal deveria criar parâmetros nacionais para servir de guia para aos governos estaduais e municipais. Diferente disso, houve uma discordância dos governadores que optaram por divergir sobre o pensamento de isolamento do governo federal.

A previsão vinculada à Organização das Nações Unidas, seria que o Brasil iria sofrer a pior crise da sociedade em décadas, com milhões de pessoas chegando à pobreza e desemprego. Porém, no Estudo Econômico da América Latina e do Caribe 2021: Dinâmica do mercado de trabalho e políticas de emprego para uma recuperação sustentável e inclusiva para além da crise da COVID-19, a CEPAL atualizou a projeção de crescimento regional do ano de 2021 para 5,9\%. Todavia, esse crescimento positivo previsto para 2021, ainda não será suficiente para recuperar os níveis de atividade econômica prépandemia. O estudo também destacou que a região terá uma desaceleração em 2022, com uma expansão estimada de 2,9\%.

(CEPAL, 2021). 
Enfim, os efeitos causados pela pandemia do novo coronavírus sobre a economia brasileira estão sendo bastante difíceis de serem mensurados. Dessa forma, alguns estudos foram utilizados para que se possa ter uma melhor dimensão do momento e a identificação de variáveis que possam contribuir para a visualização do comportamento da economia do Brasil atualmente. Nesse caso foram utilizados alguns dados do cenário econômico do país.

O Produto Interno Bruto (PIB) da indústria para 2021, teve nova previsão de alta de 6,1\% ante 6,9\% feita em julho, de acordo com dados da Confederação Nacional da Indústria (CNI). Apesar dessa revisão para baixo, o PIB brasileiro deve se expandir 4,9\%. Isso em função das expectativas mais favoráveis do setor de serviços, com o bom desempenho de tecnologia da informação, logística e serviços técnico-profissionais e com a expectativa de recuperação dos serviços prestados às famílias (CNI, 2021).

Como um exemplo de recuperação, está o Polo Industrial de Manaus, um dos principais parques industriais do Brasil, onde o desempenho também já é melhor do que antes da pandemia. Até julho/2021, o faturamento foi de mais de US\$16 bilhões, um aumento de 52,51\% em relação ao ano de 2020 (US\$ 22,88 bilhões), segundo dados dos Indicadores de Desempenho do Polo Industrial de Manaus - PIM da Superintendência da Zona Franca de Manaus - Suframa. No segmento das exportações, o PIM registrou mais de US\$ 250 milhões em faturamento no exterior no primeiro semestre de 2021, o que indica alta de 28,60\% em comparação com o resultado obtido no mesmo período em 2020 (US\$ 195 milhões) (SUFRAMA, 2021).

Figura 3: Participação dos Subsetores de atividades no faturamento do Polo Industrial de Manaus - Jan a Jul/2021 (Calculado sobre os valores em US\$).

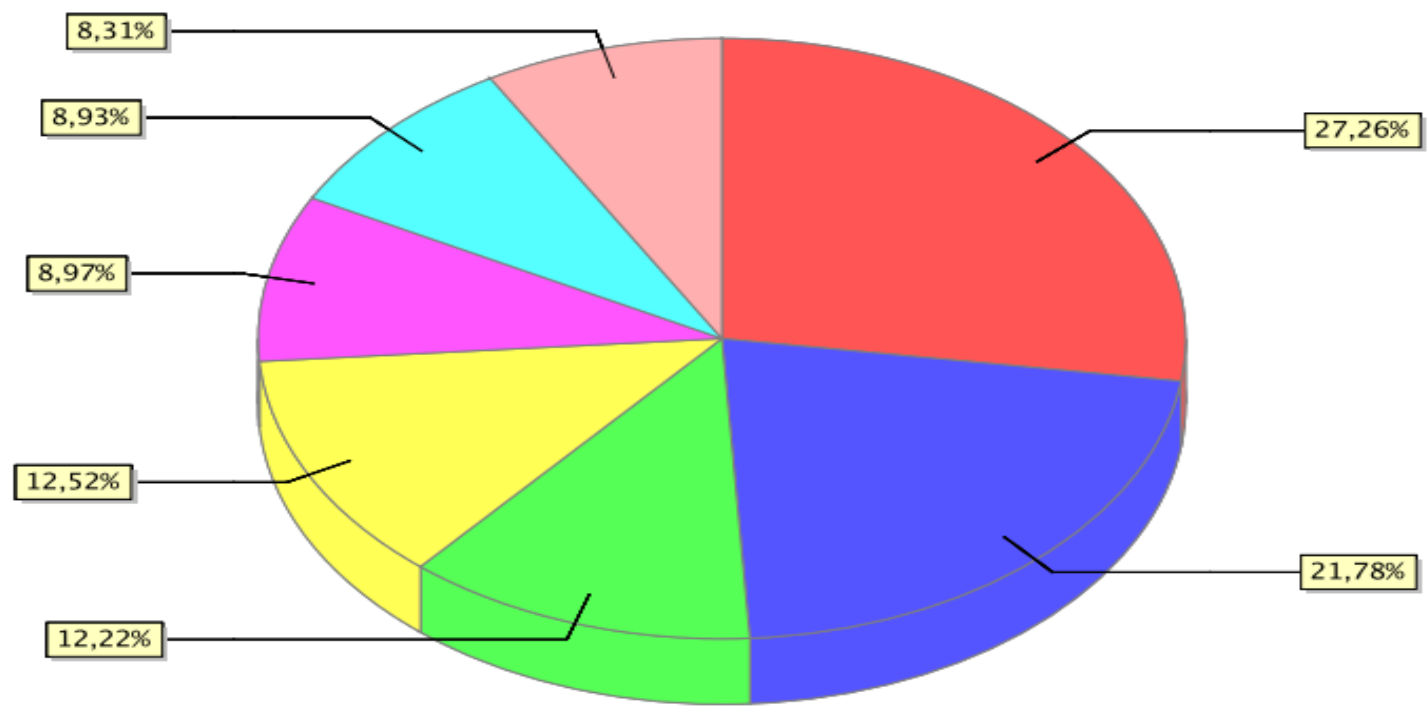

Ativar o

Bens de Informática Eletroeletrônico $\bigcirc$ Outros $\bigcirc$ Duas rodas $\bigcirc$ Termoplástico $\bigcirc$ Metalúrgico $\bigcirc$ Químico

Fonte: Indicadores de Desempenho PIM - Suframa (2021)

Pela Figura 3 acima, observa-se o faturamento em US\$ segundo os indicadores de desempenho de alguns segmentos industriais do Polo Industrial de Manaus - AM. O segmento Eletroeletrônico, com faturamento de US\$ 3,57 bilhões e crescimento de $21,70 \%$ e o de Bens de Informática. com faturamento de US\$ 4,46 bilhões e crescimento de 27,29\%, 
contribuíram com mais da metade do montante total faturado pelo até julho/ 2021. Outros segmentos que se destacaram no período foram o segmento de Duas Rodas (faturamento de US\$ 2,05 bilhões e crescimento de 12,49\%), o Químico (faturamento de US\$1,36 bilhões e crescimento de 8,30\%), o Metalúrgico (faturamento de US\$ 1,46 bilhões e crescimento de 8,92\%), o Termoplástico (faturamento de US\$ 1,47 bilhões e crescimento de 8,98\%) e o Mecânico (faturamento de US\$ 1,05 bilhões e crescimento de $6,45 \%)$.

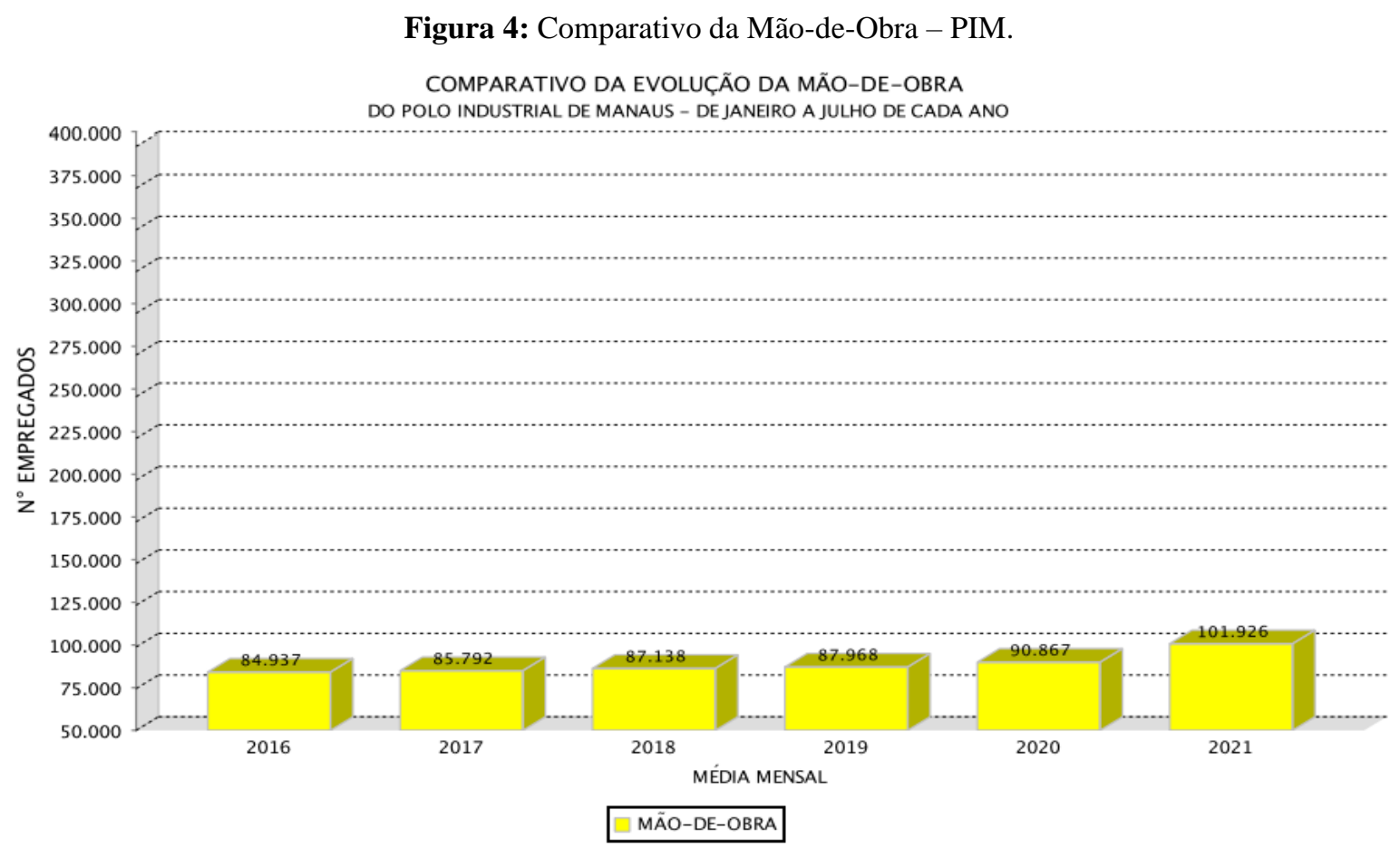

Fonte: Indicadores de Desempenho PIM - Suframa (2021).

Na Figura 4 observa-se que, quanto aos empregos, até julho/2021, o PIM registrou 101.926 trabalhadores (média mensal de trabalhadores) entre efetivos, temporários e terceirizados, o que indica um acréscimo de $12,17 \%$ em relação a 2020 (90.867 trabalhadores).

\subsection{Logística no Contexto da Pandemia}

Em 2008 vivemos uma crise global que afetou todo o mundo em particular a economia brasileira, outro evento importante foi a crise dos caminhoneiros em 2018, em que a economia brasileira ficou parada praticamente 1 mês, impossibilitado de operar devido os efeitos da greve. Foram medidas a abrangência desses 2 eventos e na primeira situação foi estimado que a economia do Brasil chegaria a crescer no ano de 2020 cerca de $2 \%$. No segundo cenário, foi investigado qual seria a consequência na economia do Brasil, se a pandemia que ainda acontece, tivesse o mesmo impacto da greve dos caminhoneiros. Neste caso, a economia brasileira não teria crescimento e acarretaria uma redução de $2 \%$ este ano (FGV, 2020).

Contudo, devido à falta de aplicação de intermodais e com desafios para melhorar a infraestrutura, o Brasil esteve passivo a sofrer em sua economia pela falta de planejamento, pretendendo a logística nacional direcionada para a realidade de cada estado, pois a tendência após isolamentos sociais é de uma necessidade logística mais intensa, para que as entregas sejam feitas, tanto local, quanto nacionalmente. 
Após os primeiros meses da pandemia mundial, a China estava se recuperando e passou a descumprir prazos de entrega dos respiradores a seus clientes, no mundo todo. Em contrapartida, alguns países pagaram mais caro e arremataram compra de respiradores que já estavam vendidos para outros países. Tais atitudes resultaram na mudança dos princípios indutores da Logística Global. Além de modificar conceitos de material estratégico (VIDEIRA, 2020).

Esta situação também foi aplicada por alguns países que ofertaram valores maiores visando monopolizar o produto que estava sendo necessário, nesse contexto, na realidade local, isso é repetido em empresas de pequeno porte, onde itens como, medicamentos, e EPI'S - equipamentos de proteção individual tivessem os preços elevados.

Além do efeito da pandemia na produção, há um efeito externo vindo dos mercados como Europa, China e Estados Unidos. Nessa situação, foi investigado o que chegaria a ocorrer com a economia no Brasil diante de uma situação de pandemia com a magnitude da crise do ano de 2008. Logo, estimou-se que nesse cenário, a queda da atividade econômica seria de 2,5\% em 2020. Em outras palavras, o efeito sobre a economia do Brasil seria uma queda de $4,0 \%$ do PIB no panorama do cenário base (Baldwin \& di Mauro, 2020). Contudo, conforme dados do IBGE, o PIB do Brasil em 2020, por exemplo, foi de $\mathrm{R} \$ 7,4$ trilhões e, no $2^{\circ}$ trimestre de 2021, o valor foi de $\mathrm{R} \$ 2.143,4$ bilhões, demonstrando um crescimento no período de $1,8 \%$ e criando uma perspectiva otimista para a economia do país IBGE (2021).

\subsection{Empresa física $x$ empresa digital}

É necessário entender de forma cautelosa, como o cliente final hoje está se comportando e quais as novas exigências de mercado, uma vez que todos necessitam de alimentação, por exemplo. E, a maneira utilizada pelos restaurantes, lanchonetes e pizzarias que estavam impedidos de abrir as portas, foi adotar um serviço de pedidos via internet e serviços de delivery (Vasconcelos \& Vasconcelos, 2020).

Esse comportamento, elevou a empregabilidade informal devido à necessidade urgente e rápida de entregadores $\mathrm{e}$ funcionou como um marco para as empresas investirem em um ramo que já estava disposto, porém apenas algumas empresas agregavam em seu portfólio, que é essa modalidade de compra online e com entrega grátis ou não. E, essa quebra de paradigma para essas empresas, acarretou sua sobrevivência e em alguns casos, em seu crescimento.

No trabalho de Xavier et. al. (2020) que estudou as redes sociais visando uma estratégia como apoio para vigilância sanitária e em saúde durante a pandemia da COVID-19, o resultado obtido demonstrou ótimas perspectivas, não apenas para o âmbito da vigilância sanitária, pois os resultados identificaram várias informações úteis para a empresa, obtidas através de métodos computacionais, na qual fornecem uma visão em tempo real, sendo útil para a tomada de decisão da empresa.

Outras empresas também tiveram que se reinventar, como as empresas de vendas e prestação de serviços que passaram a adotar mais serviços online para ter acesso ao cliente final e, para atendimento em domicílio, passaram a atender exigências higiênico sanitárias conquistando confiança do cliente para a contratação do serviço. Empresas globais como a Amazon e, no Brasil, o Mercado Livre, são empresas exemplos em seu pioneirismo referente a compras online e sistema de entrega, um sistema que traz em si praticidade e comodidade para os seus clientes. A Amazon é hoje reconhecida mundialmente pelo investimento em pesquisa e desenvolvimento, visando a melhoria de entrega para o cliente final, novos modais logísticos e a redução no seu tempo de entrega.

\subsection{Crise Sanitária e Econômica}

Acredita-se que um cenário mais realista, talvez seja a junção desses dois fenômenos pois a economia mundial sofrera muito com a corona vírus e a economia brasileira estava paralisada. Então, foi simulado um cenário de maior gravidade em que o efeito da crise do corona vírus corresponderia à greve dos caminhoneiros ocorrida no ano de 2018 ou até mesmo com a crise de 2008, neste cenário dramático, a economia poderia cair em até 4,5\%, na soma de todos os efeitos, o Brasil sairá de um 
cenário base de $2 \%$ para $-4,5 \%$ praticamente uma queda de 6,5\% (Baldwin \& di Mauro, 2020). Esse cenário também precisou ser revisto, pois a previsão da Dimac/Ipea para o crescimento do PIB em 2021 permaneceu inalterada - ficando em 4,8\% (IPEA, 2021).

Diferentes pesquisas acusam a crise econômica oriunda da paralização dos caminhoneiros como uma crise de grande magnitude. Logo vemos a importância da aplicação de outros modais de transporte logístico, pois essa situação mostrou a dependência do Brasil a um único meio de transporte.

As empresas no Brasil passaram a buscar ajuda financeira com os bancos e então o governo, além de fornecer ajuda financeira em diversos tipos de programas de crédito empresarial, também aplicou decreto flexibilizando as obrigações trabalhista, possibilitando o afastamento temporário, a redução da jornada de trabalho e salário e demissões com pagamento de rescisões parceladas, ou mesmo a opção de férias coletivas. Contudo, como grande parte das empresas não possuírem um planejamento estratégico, acabaram ficando sem fluxo de caixa, ou sem reserva emergencial, forçando muitas dessas empresas a danos irreparáveis e até mesmo à falência, por não conseguirem se manter durante esse período. Atualmente, mesmo as cidades tentando retornar à normalidade, ainda assim o número de novos indivíduos infectados pela pandemia, ainda é uma realidade (Vasconcelos \& Vasconcelos, 2020).

As estimativas que estão sendo feitas podem ser realistas, porém somente o tempo irá dizer e, para que tenhamos um simulado racional, pessimista ou otimista, vai depender dos fatores e do grau da pandemia. Ou seja, se não mantivermos o controle da pandemia na produção, a economia de um país poderá se desorganizar e além das perdas de seus cidadãos, poderá ocorrer uma recessão considerável.

E, uma vez que a pandemia seja controlada, poderemos todos conseguir voltar a uma certa normalidade a curto prazo, mas 2022 e 2023 serão anos da retomada da trajetória (Baldwin \& di Mauro, 2020).

\section{Considerações Finais}

$\mathrm{Na}$ teoria, todas as empresas necessitam de estratégias de negócios. Porém, de nada adianta apenas possuir estratégias. É importante que as empresas executem essas estratégias, transformando planos em realidade, elevando o seu nível no mercado, pois estratégias são definidas com observação no cenário de negócios, verificando todos os pontos de vista e probabilidades possíveis.

Em virtude dos fatos mencionados, somente um plano de reativação por parte das autoridades e da Organização Mundial da Saúde, poderá mudar de fato o cenário de aflição econômica e social mundial causado pela pandemia do COVID 19. E o Brasil, necessita continuar lutando para vencer a pandemia e ter condições se reestruturar e consequentemente permitir, a todos os cidadãos, voltar ao trabalho de maneira segura e eficiente.

Não há respostas corretas ou estratégias simplificadas frente a situações de incertezas, abrangendo uma crise global. É necessária uma nova economia, que o sistema nacional de saúde tenha mais cuidados e cautela com os investimentos do Estado e principalmente, que nossos governantes tenham mais serenidade e empatia para com o seu povo. Hoje, ainda sobre o impacto de toda a catástrofe que trouxe essa pandemia, os responsáveis pelas empresas já conseguem ver a importância em desenvolver estratégias prévias e bem consolidadas, que permitam uma reação rápida às mudanças no comportamento do mercado e possibilitem sua sobrevivência e a retornada à normalidade sem grandes traumas e prejuízos para essas corporações.

Este estudo é de suma importância para demonstrar que hábitos empresariais de planejamento estratégico e controle de crise podem fazer a diferença entre os níveis de sobrevivência e sucesso das empresas em tempos difíceis. Serão importantes novos estudos, nos próximos anos após a pandemia do COVID-19, que analisem e comparem os resultados das 
empresas quanto à influência de estratégias de negócios, na tomada de decisões. Com certeza, haverá uma nova percepção empresarial a esse respeito

\section{Referências}

Alves, R. S. S., Sousa, F. L. L. de., Leite, A. C., Silva, M. P. B., Barbosa, T. C., Barbosa Júnior, L., Serra, J. L., Soares, I. L., Fagundes, G. R. S., Silvestre, F. E. R., Silva, L. A. C. da, Resende, C. A. A., Silva, J. K. A. da, Lima, A. C. ., Mesquita , G. N. de, \& Borges, P. R. P. (2020). Combating COVID - 19: A look at prevention measures with an emphasis on social isolation. Research, Society and Development, 9(12), e47991210627. https://doi.org/10.33448/rsdv9i12.10627

Baldwin, R. E., \& di Mauro, W. (2020). Mitigating the COVID economic crisis. Centre for Economic Policy Research.

Baldwin, R., \& di Mauro, B. W. (2020). Economics in the Time of COVID-19. A VoxEU. org Book, Centre for Economic Policy Research, London.

Barro, R. J., Ursúa, J. F., \& Weng, J. (2020). The coronavirus and the great influenza pandemic: Lessons from the "spanish flu" for the coronavirus's potential effects on mortality and economic activity (No. w26866). National Bureau of Economic Research. DOI 10.3386/w26866

Bastos, S. B., \& Cajueiro, D. O. (2020). Modeling and forecasting the early evolution of the Covid-19 pandemic in Brazil. Scientific Reports, 10(1), 1-10.

CEPAL. Comissão Econômica Da América Latina. Boletim COE COVID-19. $\quad$-Número $13 \quad-20 \quad$ de $\quad$ abril de 2020. https://portalarquivos.saude.gov.br/image/pdf/2020/April/21/BE13Boletim-do-COE.pdf

Chauhan, V., \& Shah, M. H. (2020). An empirical analysis into sentiments, media consumption habits, and consumer behaviour during the Coronavirus (COVID-19) outbreak. Purakala, 0971-2143.

Chizzotti, A. (1995). Pesquisa Experimental e Pesquisa Qualitativa. Pesquisa em Ciências Humanas e Sociais. Cortez.

de Morais, J. K. R., \& de Almeida, J. M. T. (2021). Psicoterapia Dialógica Gestáltica Como Mecanismo De Sobrevivência Em Tempos De Pandemia.

CNI - Confederação Nacional da Indústria (2021). http://www6.sistemaindustria.org.br/gpc/externo/estatisticaAcessoSistemaExterno.faces

Eurostat \& Rating. A. (2021). Desempenho do PIB do Brasil no $2^{\circ}$ trimestre fica em $38^{\circ}$ em ranking de 48 países. https://g1.globo.com/economia/noticia/2021/09/01/desempenho-do-pib-do-brasil-no-2o-trimestre-fica-em-38o-em-ranking-de-48-paises.ghtml

Estrela, C. (2018) - Metodologia Científica: Ciência, Ensino, Pesquisa. Editora Artes Médicas.

Fernandes, A. M., Bruchêz, A., d'Ávila, A. A. F., Castilhos, N. C., \& Olea, P. M. (2018). Metodologia de pesquisa de dissertações sobre inovação: Análise bibliométrica. Desafio online, 6(1).

FGV - Fundação Getúlio Vargas (2021), Monitoramento PIB mensal 2021. https://portalibre.fgv.br/sites/default/files/2021-10/monitor-do-pib-fgv-outubro-de2021-ref.-de-agosto.pdf

Guimbeau, A., Menon, N., \& Musacchio, A. (2020). The brazilian bombshell? the long-term impact of the 1918 influenza pandemic the south american way (No. w26929). National Bureau of Economic Research.

IBGE - Instituto Brasileiro de Geografia e Estatística, População. (2020). https://www.ibge.gov.br/apps/populacao/projecao/index.html? utm_source=portal\&utm_medium=popclock\&utm_campaign=novo_popcloc

IBGE - Instituto Brasileiro de Geografia e Estatística, População. (2021). https://www.ibge.gov.br/indicadores

Instituto de Pesquisa Econômica Aplicada - IPEA (2021). https://www.ipea.gov.br/cartadeconjuntura/index.php/tag/pib/

Moretti, SL do A., Gabriel, MLD da S., do Prado, RADP, \& Fagundes, AFA (2021). Comportamento do consumidor durante a pandemia do COVID-19: análise latente de classes sobre atitudes de enfrentamento e hábitos de compra. Management Studies, 37 (159), 303317. https://doi.org/10.18046/j.estger.2021.159.4433

Oliveira, E. N., Costa, M. S. A., Nascimento, P. I. da F. V. do, Rodrigues, C. S., Andrade, C. S. G. de, Mendonça, J. M. F., Pinto, M. R., França, S. da S., \& Lima, G. F. (2020). With the word, health professionals who are at the front line of COVID-19 combat. Research, Society and Development, 9(8), e30985145. https://doi.org/10.33448/rsd-v9i8.5145

Organização Mundial da Saúde - OMS. Ministério da Economia. Bases Estatísticas da RAIS: dados de 2012.Brasília, 2020.

Organização Pan Americana de Saúde - OPAS (2020) https://www.paho.org/pt/brasil

Pimentel, A. do S. G., \& Silva, M. de N. R. M. de O. (2020). Psychic Health in Times of Corona Virus. Research, Society and Development, 9(7), e11973602. https://doi.org/10.33448/rsd-v9i7.3602

Silva, A. C. R. (2003). Metodologia da pesquisa aplicada. Atlas.

Silva, A. J. H. D. (2014). Metodologia de pesquisa: conceitos gerais.

Silva, M. de N. R. M. de O., \& Pimentel, A. do S. G. (2021). Unveiling social isolation in the daily life of the COVID 19 pandemic. Research, Society and Development, 10(3), e59910314132. https://doi.org/10.33448/rsd-v10i3.14132 
Research, Society and Development, v. 10, n. 15, e419101523048, 2021

(CC BY 4.0) | ISSN 2525-3409 | DOI: http://dx.doi.org/10.33448/rsd-v10i15.23048

Sheth, J. (2020). Impact of Covid-19 on consumer behavior: Will the old habits return or die? Journal of business research, 117, 280-283. https://doi.org/10.1016/j.jbusres.2020.05.059

SUFRAMA - Superintendência da Zona Franca de Manaus (2021). Indicadores do Polo Industrial de Manaus - PIM. https://www.gov.br/suframa/ptbr/publicacoes/estudos-socioeconomicos

Vasconcelos, P. S., \& Vasconcelos, P. E. A. (2020). Desafios da Estratégia Empresarial: antes, durante e após a pandemia de 2020. Revista Interdisciplinar do Direito-Faculdade de Direito de Valença, 18(1), 163-182.

Videira, A. C. (2020). Logística Nacional no Pós-Pandemia.

Xavier, F., Olenscki, J. R. W., Acosta, A. L., Sallum, M. A. M., \& Saraiva, A. (2020). Análise de redes sociais como estratégia de apoio à vigilância em saúde durante a Covid-191. Estudos avançados, 34, 261-282. https://doi.org/10.1590/s0103-4014.2020.3499.016 